\title{
Polymorphous low grade adenocarcinoma of the parotid gland: A case report with cytohistological correlation and its immunohistochemical study
}

\author{
Shrestha $\mathrm{S}^{1}$, Pun $\mathrm{CB}^{1}$, Basyal $\mathrm{R}^{1}$, Pathak $\mathrm{T}^{1}$, Bastola $\mathrm{S}^{1}$, Neupane $\mathrm{S}^{1}$, Lee $\mathrm{MC}^{1}$ \\ ${ }^{I}$ Department of Pathology, B.P. Koirala Memorial Cancer Hospital, Bharatpur, Nepal.
}

\author{
Keywords: \\ Parotid; \\ Polymorphous low-grade \\ adenocarcinoma; \\ Salivary gland neoplasm
}

\begin{abstract}
Polymorphous low-grade adenocarcinoma is a rare salivary gland malignant tumor of low aggressiveness, commonly occurring in minor salivary glands. Its origin in major salivary glands is considered exceedingly rare. We report a case of polymorphous low grade adenocarcinoma arising from left parotid in a 21-yearold female patient.
\end{abstract}

\section{INTRODUCTION}

Polymorphous low-grade adenocarcinoma (PLGA) is a low-grade malignant tumor of salivary glands, most often arising from minor salivary glands with palate being a common site. Much less frequently cases have been described in major glands, usually but not always against a background of pleomorphic adenoma. ${ }^{1}$ Histologically various architectural patterns (like lobular, papillary and solid) are seen with bland cytological features. Infiltration into the surrounding tissues is focally seen. We report a case of PLGA arising from parotid gland.

\section{CASE REPORT}

A 21-year-old female patient presented with complaint of a painless left parotid gland swelling for six months. On examination there was a non- tender, firm to hard nodular

\section{Correspondence:}

Dr. Sadina Shrestha, MD

Department of Pathology, B.P. Koirala Memorial Cancer Hospital, Bharatpur, Nepal.

Email: sadina_shrestha@yahoo.com mass in the left retroauricular region with intact facial nerve and measured $4.5 \times 3.0 \mathrm{~cm}$.

\section{Pathological Evaluation}

\section{Cytologic findings}

The FNAC smears were air dried and then stained with a Giemsa stain. The aspirate smears were hypercellular, consisting mainly of branching papillary clusters and sheets of bland, uniform cell with round to oval nuclei; dispersed chromatin; and absent or inconspicuous nucleoli. The cells generally had scant to moderate amount of dense cytoplasm (fig. 1). Occasionally, these cells formed tubular structures containing spherical, hyaline globules and stromal fragments, similar to those seen in adenoid cystic carcinoma (fig. 2). Mitosis and pleomorphism were absent. A cytological interpretation was low-grade papillary neoplasm of salivary gland (Fig.3A\&B).

The mass was surgically excised through superficial parotidectomy with facial nerve preservation. The excised tumor mass was sent for histopathological evaluation. 


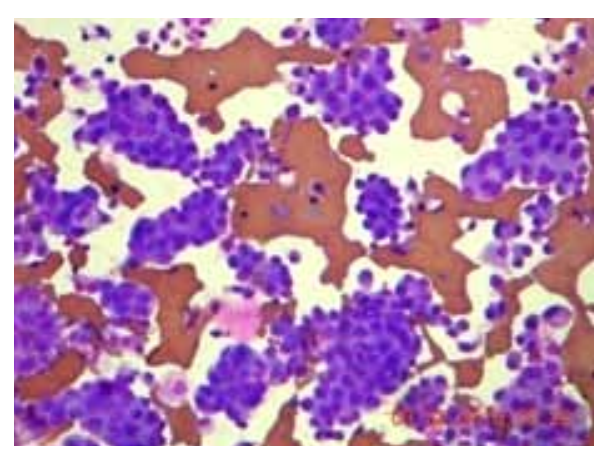

Figure 1: FNA smears showing tumor cells in pseudopapillae and clusters, of uniform cells with bland nuclei(Giemsa stain, X100)

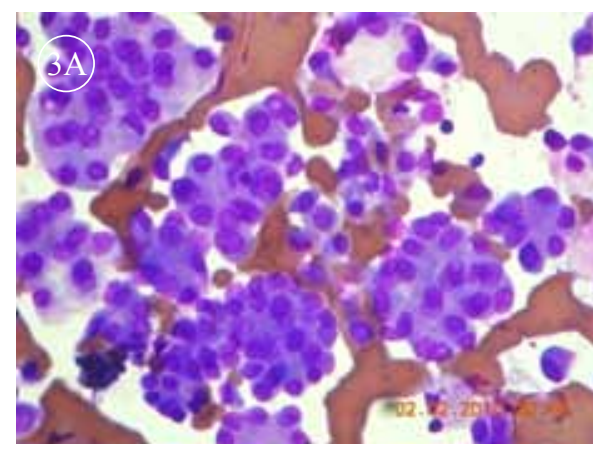

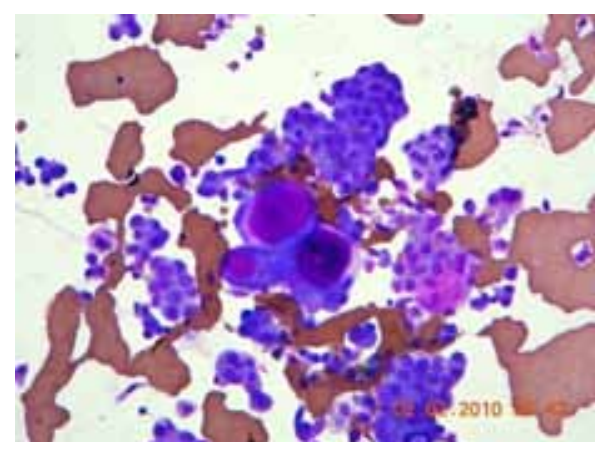

Figure 2: Bland uniform cells and hyaline globules, similar to those seen in adenoid cystic carcinoma(Giemsa stain, X100)

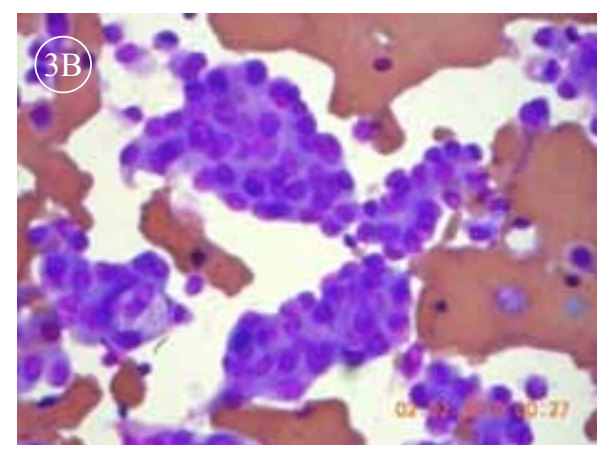

Figure 3A\&B: FNA showing pseudopapillary fragments, clusters and single epithelial cells containing round to oval cells and moderate amount of cytoplasm (Giemsa stain, X200)

Grossly, the tumor was relatively well-circumscribed, lobulated and measured $3.0 \times 3.0 \times 1.5 \mathrm{~cm}$; cut section was solid, pale white, homogeneous and firm. Adjacent normal looking salivary gland measured $1.5 \times 1.0 \times 0.5 \mathrm{~cm}$.

Microscopically, tumors were poorly circumscribed, with infiltrative margins and had a polymorphous architecture pattern, including lobular, papillary, glandular and solid, with predominance of first two types (fig.5\&6). The papillae, glands and tubules were lined by a single layer of cuboidal cells. The cells were round to ovoid to polyhedral, with the cytoplasm varying from eosinophilic to clear. Nuclear features were bland with vesicular nucleus, some showing inconspicuous nucleolus (fig. 5). Hyperchromasia or mitoses were not seen. Lumen showed eosinophilic material at places, which was variably PAS positive. Neither perineural invasion nor vascular permeation was seen. Rest of the salivary gland tissue showed varying proportions of chronic sialadenitis.

Immunohistochemical examination was performed in tumor tissue by using monoclonal antibodies (DAKO) with antigen-antibody streptavidin immunoperoxidase technique. Tumor cells showed strong positivity to S-100, epithelial membrane antigen (EMA) and cytokeratin (CK) (AE1/ AE3) (fig. 7, 8, 9). These immunohistochemical findings indicate that the tumor is consistent with the diagnosis of polymorphous low grade adenocarcinoma.

\section{DISCUSSION}

PLGA was first described simultaneously in 1983 by two groups of researchers under different names. Bataskis et al named it as lobular carcinoma. At present, this neoplasm is well recognized and known as PLGA..$^{2-4}$ The first cases of a PLGA arising from the parotid were published almost simultaneously in 1991 by George et $\mathrm{al}^{5}$ and Miliauskas. ${ }^{6}$ PLGAs account for $10 \%$ all tumors of minor salivary glands and $25 \%$ of all malignancies of the minor salivary glands. PLGA occurs almost exclusively in minor salivary gland and its origin in a major salivary gland is considered rare. Although several report have described PLGA of the major salivary glands. ${ }^{1,4,6,7-8}$

Experience with cytology diagnosis is limited to some case reports..$^{9-11}$ FNA is widely used in other head and neck sites, including the major salivary glands and cervical lymph nodes. PLGA may enter the differential diagnosis in these sites. One of the main differential problems is with adenoid cystic carcinoma. The cytologic preparation shows cellular smear with small cells forming tubular spaces containing hyaline globules in both tumor. The differences are subtle but may be appreciated when, due to presence of papillary structure and uniform, bland round to oval cells which favoring features of PLGA. ${ }^{11}$

PLGA should be distinguished cytologically from 


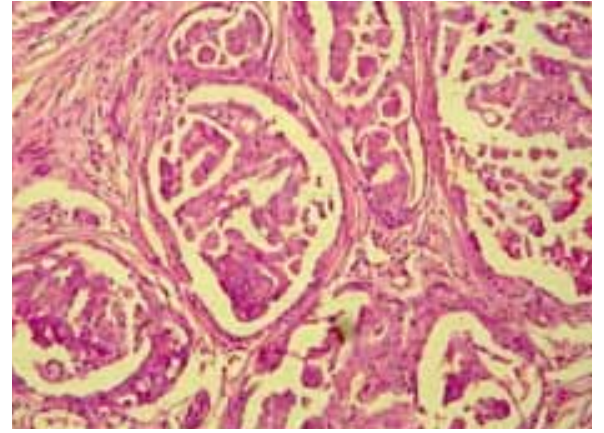

Figure 5: Tumor with lobular and papillary growth pattern (HE stain, X100).

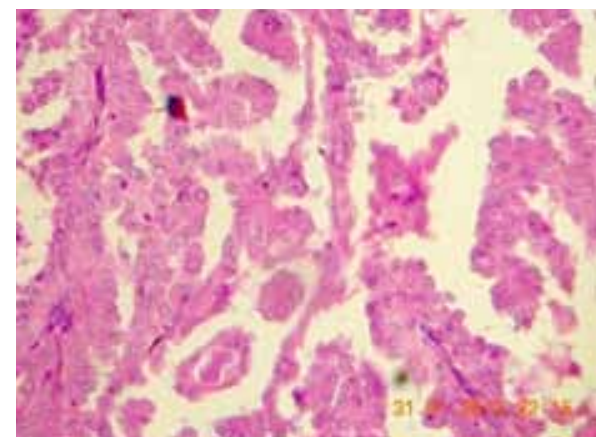

Figure 6: A branching papillary cluster of uniform cells (HE stain, X200).

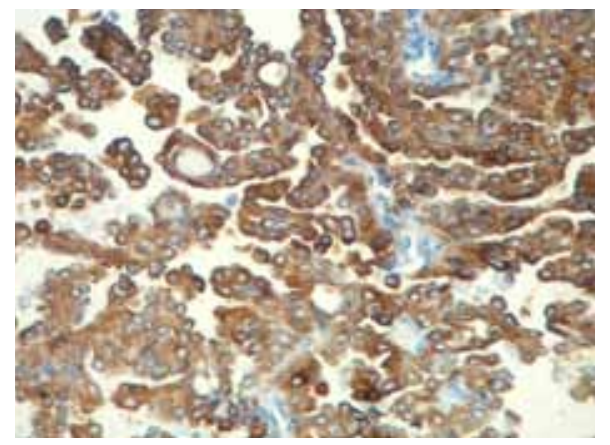

Figure 7: Tumor cells showing cytoplasmic S-100 positivity (Original Magnification, X200)

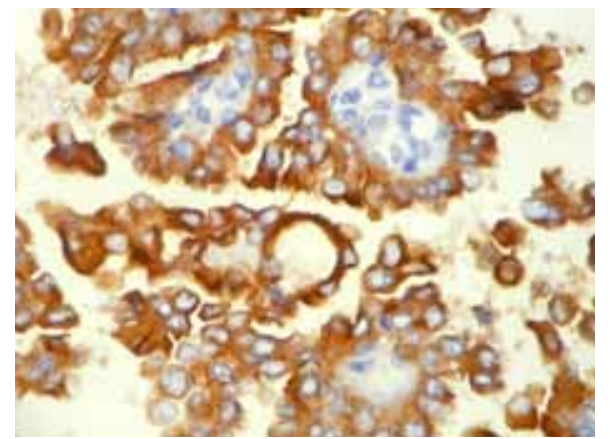

Figure 8: Tumor cells showing cytoplasmic EMA positivity (Original Magnification, X400).

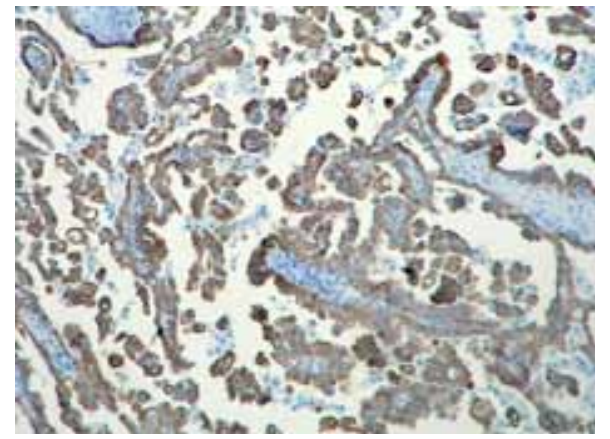

Figure 9: Tumor cells showing cytoplasmic cytokeratin (AE1/AE; Original Magnification, X100).

peomorphic adenoma and papillary cyst adenocarcinoma (PCAC). In pleomorphic adenoma, there is presence of both epithelial and mesechymal components. The spindled myoepithelial cells are admixed and interdigitate with the ground substance, a features not seen in PLGA. Epithelial cells are rarely arranged in tubular structures around hyaline deposits, as may be observed in PLGA. PCAC is composed of clusters of uniform cells with rare papillae. The cells of PLGA are similar but papillae seem to be more frequent. Moreover, hyaline globules are not seen in PCAC.?

Histomorphologically various architectural patterns could be seen in different areas (lobular, papillary glandular, and solid). Luminal eosinophilic material were seen in some area. Compared with minor salivary gland tumors, parotid PLGAs tend to (1) have a more uniform histologic structure, (2) contain papillary structures more often, and (3) exhibit less perineural invasion. ${ }^{8}, 12$ PLGA cytology is characterized by the presence of cuboidal cells with abundant cytoplasm, round to oval nuclei, and inconspicuous nucleoli. ${ }^{11,13}$ Mitotic figures are rarely seen. ${ }^{11}$

Immunohistochemical staining can assist in making a diagnosis of PLGA, as $90 \%$ of cells stain positively with S-100 protein and EMA. ${ }^{13}$ The results of staining with cytokeratin (CK) (AE1/ AE3) are somewhat more variable, as 75 to $95 \%$ of the cells stain positively. ${ }^{13}$ The tumor cells were negative for carcinoembryonic antigen (CEA).

The differential diagnoses of PLGA include adenoid cystic carcinoma (ACC), and pleomorphic adenoma (PA). Both ACC and PLGA can have similar architectural patterns; however, the cells in ACC tend to be smaller with hyperchromatic angulated nuclei and coarser chromatin. Mitoses are numerous. Finally, while PLGAs stain widely with S-100 protein and EMA, adenoid cystic carcinomas stain much less diffusely. ACC is positive for CEA but not S-100 protein. ${ }^{14}$ It is important to differentiate these two entities, as the prognosis and treatment are significantly different.

Unlike PLGA, pleomorphic adenoma (PA) is nearly always circumscribed and is composed of proliferating 
stromal, epithelial and myoepithelial cells. In addition, the myxochondroid and chondroid areas present in PA are not evident in PLGA. ${ }^{15}$ Various immunohistochemical markers have been found to be positive like vimentin, cytokeratin, S-100, CEA, SMA and GFAP. Glial fibrillary acidic protein (GFAP) is negative in PLGA. ${ }^{16}$

\section{CONCLUSION}

PLGA is relatively new entity of salivary gland tumor though common in minor glands can arise from the major salivary gland. Cytological diagnosis of PLGA alone is difficult as its features overlap considerably with those of other salivary gland tumors. However, histopathological correlation and its immunohistochemical study are indicated to confirm diagnosis of PLGA.

\section{ACKNOWLEDGEMENT}

The authors wish to thank Mr. M. Sapkota for his technical support.

\section{REFERENCES}

1. Arathi N, Bage AM. Polymorphous low-grade adenocarcinoma of parotid gland: A rare occurrence. Indian J Pathol Microbiol 2009;52:103-5.

2. Batsakis JG, Pinkston GR, Luna MA, Byers RM, Sciuba JJ, Tillery GW. Adenocarcinoma of the oral cavity: a clinic-pathologic study of terminal duct carcinomas. J Laryngol Otol 1983;97:825-35.

3. Freedman PD, Lumerman H. Lobular carcinoma of the introral minor salivary gland origin. Report of twelve cases. Oral Surg Oral Med Oral Pathol 1983;56:57-66.

4. Katoh T, Yoshihara T, Kaneko $\mathrm{T}$ et al. A case of polymorphous adenocarcinoma in the right parotid gland. Gan No Rinsho
1985;31:861- 4 .

5. George MK, Mansour P, Pahor AL. Terminal duct carcinoma. J laryngeal Otol 1991;105:781-7.

6. Miliauskas JR, Plomorphous low grade (terminal duct) adenocarcinoma of the parotid gland. Histopathology 1991;19:555-7.

7. Jerzy Klinjaneiko, Phillipe Vielh. Salivary carcinoma with papillae. Cytology and histology analysis of polymorphous low grade adenocarcinoma and papillary cyst adenocarcinoma. Diagn cytopathol. 1998;19:244-9.

8. Merchant WJ, J, Cook, Eveson J W. Polymorphous low grade adenocarcinoma of parotid gland. Br J Oral Maxillofac Surg 1996;34:328-30.

9. Frierson HF Jr, Covell JL, Mills SE. Fine needle aspiration cytology of terminal duct carcinoma. Diagnostic cytopatholol. 1987;3:159-62.

10. Clevelandet DB, Cosgrov MM, Martin SE. Tyrozine rich crystalline in fine needle aspiration of polymorphous low grade adenocarcinoma. A case report. Acta Cytolol. 1990;38:274-51.

11. Gibson D, Saboorien HM. Fine needle aspiration of polymorphous low grade adenocarcinoma in salivary gland. Cancer. Cancer Cytopathology.1999;87:31-6.

12. Kemp BL, Batsakis JG, Naggar AK et al. Terminal duct adenocarcinoma of the parotid gland. J Laryngol Otol 1995;109:4668.

13. Gnepp DR, Chen JC, Waren C. Polymorphous low-grade adenocarcinoma of minor salivary gland. An immunohistochemical and clinicopathologic study. Am J Surg Pathol 1998;12:461-8

14. Cheuk W, Chand JKC, Christopher D, Fletcher M. Adenoid cystic carcinoma, salivary gland tumors, In: Diagnostic Histopathology of tumors (Vol I). Philadelphia: USA. 2002.pp269.

15. Everson JW, Auclair P, Gnepp DR. Polymorphous low grade adenocarcinoma. Tumors of salivary gland, In: World Health organization classification of Pathology and Genetics of Head and neck tumors. IARC:Lyon; 2005.pp223-4.

16. Nagao T, Gaffea $\mathrm{H}$, TA, et al. Polymorphous low grade adenocarcinoma of the major salivary glands. Reports of three cases in an unusal location. Histopathology 2004;44:164-71. 